\title{
BIDIRECTIONAL DC-DC CONVERTER WITH COUPLED INDUCTOR FOR DC-BUS REGULATION IN MICROGRID APPLICATIONS
}

\author{
Robson Mayer ${ }^{1,2}$, Menaouar Berrehil El Kattel ${ }^{1,3}$, Sérgio Vidal Garcia Oliveira ${ }^{1,4}$ \\ ${ }^{1}$ Universidade do Estado de Santa Catarina - UDESC, Joinville - SC, Brazil \\ ${ }^{2}$ Centro de Tecnologia da Informação Renato Archer - CTI, Campinas - SP, Brazil \\ ${ }^{3}$ Universidade Federal de Minas Gerais - UFMG, Belo Horizonte - MG, Brazil \\ ${ }^{4}$ Universidade Regional de Blumenau - FURB, Blumenau - SC, Brazil \\ e-mail: mayerrobson@gmail.com, berrehilelkattel@gmail.com, sergio_vidal@ieee.org
}

\begin{abstract}
This paper presents a theoretical analysis and the experimental results of the bidirectional coupled inductor dc-dc converter for dc-bus voltage regulation and power compensation in dc-microgrid applications. In dc-microgrids, a power distribution system requires a bidirectional converter to control the power flow between dc-bus and batteries. Furthermore, the dc-bus needs to be kept stabilized within certain limits and the converter handles a large range of voltage variation in the accumulators. The proposed topology is also relatively feasible for low-input-voltage applications for interfacing energy storage elements, such as batteries, ultracapacitors with the high voltage dc-bus in electric vehicles. The converter allows greater voltage gain compared to classic non-isolated topologies and can better deal with the wide range of voltage variation imposed by the source/load. The operation principles, the DC voltage gain, the design of the filters, the voltage/current stresses and a comparison are discussed. The experimental results confirmed and validated the theoretical study as well as the converter performance so that the measurements performed obtained from a $600 \mathrm{~W}$ laboratory prototype.
\end{abstract}

Keywords - Bidirectional dc-dc converter, Coupled inductor, Energy storage system, Microgrid.

\section{INTRODUCTION}

In recent years, the microgrids have been continuously growing, especially hybrid systems that use many elements in direct current [1]. However, it is worth noting that energy storage systems with lithium-ion batteries are the main technology used for the new storage capacity [2], [3]. A DC microgrid can be described as a grid subsystem that allows the interconnection of distributed generators, power generation elements, energy storage, and local loads within a restricted region. Hybrid microgrids are composed of $\mathrm{AC}$ and $\mathrm{DC}$ subgrids, as shown in Figure 1, which are linked by one or more interface converter [4]. Microgrid must provide a secure and economical operation at all times for the system, while simultaneously providing a high level of reliability in the bus voltage for local loads. In the event of disconnection or AC-bus failures or any fluctuation in the photovoltaic generation, as discussed in [5], the dc-dc converter is used

Manuscript received 02/23/2020; first revision 06/04/2020; accepted for publication 07/06/2020, by recommendation of Editor Demercil de Souza Oliveira Jr. http://dx.doi.org/10.18618/REP.2020.3.0007 as a strategy to provide effective regulation of the DC-bus voltage [6]. The stability of DC-bus voltage is very important and when the microgrid is connected to the utility grid, the bus voltage is regulated by the AC-DC converter. However, when the microgrid works in an islanded operation, DC-bus voltage must be regulated by renewable energy generations and storage systems [7].

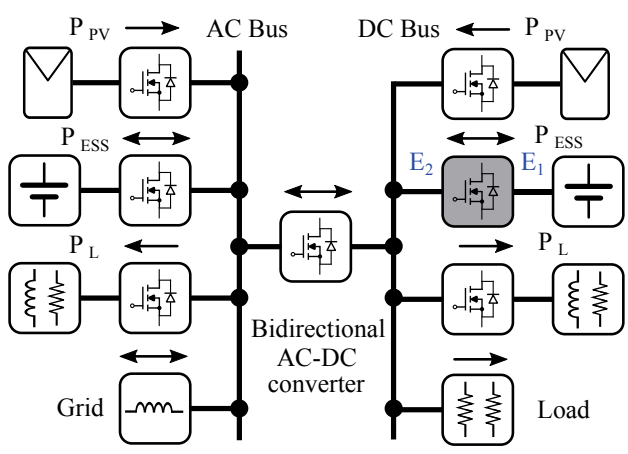

Fig. 1. Hybrid AC/DC microgrid system.

Advanced electronics industry technology is already using several types of power converters with varying degrees of performance that are available, as in the case of applications in microgrids and electric vehicles (EVs) [8]-[10]. Power electronic converters are considered, together with batteries, the key elements in EVs, where they connect the power sources to the drive train of the vehicle [11],[12]. The DC-DC converter is used to allow a desired level of dc voltage to be obtained without having to increase the battery bank size. In [13], the proposed study presents a bidirectional converter that functions as an interface between the DC-link and energy storage systems. This topology is used to adapt the voltage levels of the system onboard the EVs or in case of braking energy recovery.

This paper provides the theoretical analysis, a comparison between of the proposed converter and previous coupled inductor and experimental result of the proposed bidirectional DC-DC converter in continuous conduction mode (CCM). Therefore, a prototype was built, tested and evaluated to prove the theoretical analysis and confirm its potential.

\section{PROPOSED COUPLED INDUCTOR BIDIRECTIONAL DC-DC CONVERTER}

In this section, the theoretical analysis and the operating stages for CCM are presented. Some simplifications are adopted and the components are considered ideals. The 
converter operates in a steady-state and the variation of the energy stored in the inductors and capacitors is zero in a switching period $T_{S}$ and, the volt-second balance is applied.

Figure 2 shows the topology of the bidirectional DC-DC converter with coupled inductor (also known as the bidirectional coupled inductor non-isolated DC-DC converter) which was proposed in [13]. The circuit is composed by three power switches $S_{1}, S_{2}$ and $S_{3}$, one coupled inductor ( $L_{1}$ and $L_{2}$ ), two filter capacitors $C_{1}$ and $C_{2}$, and dc sources $E_{1}$ and $E_{2}$. The topology has fewer components as compared to the bidirectional cascade, Buck-Boost, Cuk and Interleaved bidirectional dc-dc converters [14]-[17], it allows bidirectional power flow between dc sources $E_{1}$ and $E_{2}$. In general, the proposed converter operation can be divided into two operating modes; forward operating mode and the backwards operating mode. In forward operating mode, the power flow from $E_{1}$ to $E_{2}$ is obtained by modulating $S_{2}$, keeping $S_{1}$ turned-on and $S_{3}$ turned-off. In backwards operating mode, the power flow from $E_{2}$ to $E_{1}$ is obtained by modulating $S_{3}$, keeping the switches $S_{2}$ and $S_{1}$ turned-off.

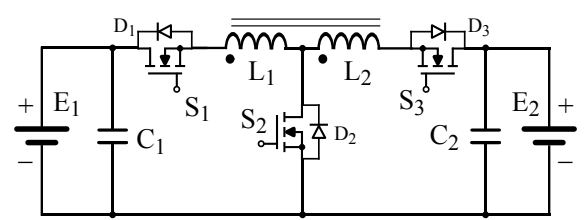

Fig. 2. Topology of the bidirectional coupled inductor DC-DC converter.

The turns ratio of the coupled inductor is defined by (1). Where the $n_{1}$ is the turns number of winding $L_{1}$, and $n_{2}$ is the turns number of winding $L_{2}$.

$$
n=\frac{n_{2}}{n_{1}}=\sqrt{\frac{L_{2}}{L_{1}}} .
$$

Where:

$L_{1} \quad$ - The inductance value of the winding $n_{1}$;

$L_{2} \quad$ - The inductance value of the winding $n_{2}$.

\section{A. Forward Operating Mode ( $E_{1}$ to $\left.E_{2}\right)$}

In CCM, the inductor currents $i_{L 1}$ and $i_{L 2}$ will not reach zero. Based on this, the circuit operation in a switching period $T_{S}$ can be divided into two stages, as shown in Figures 3.a and 3.b. Figure 4 adequately demonstrates the main idealized waveforms of the proposed topology in forward operating mode. The operational modes are described in the following.

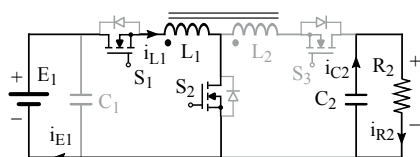

a)

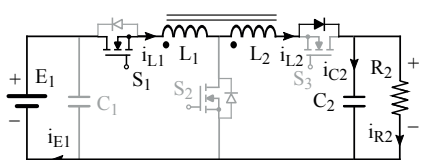

b)
Fig. 3. Topological stages in forward operating mode for CCM: a) First stage, and b) Second stage.

In this operation mode, the power switch $S_{1}$ remains conducting on all operating time, therefore the waveforms of $S_{1}$ are unshown in Figure 4.

$1^{\mathrm{o}}$ stage $\left[0-D T_{S}\right]$ : This stage starts at instant $t_{0}$, when the switches $S_{1}$ and $S_{2}$ are turned-on. The input current $i_{E 1}(t)$

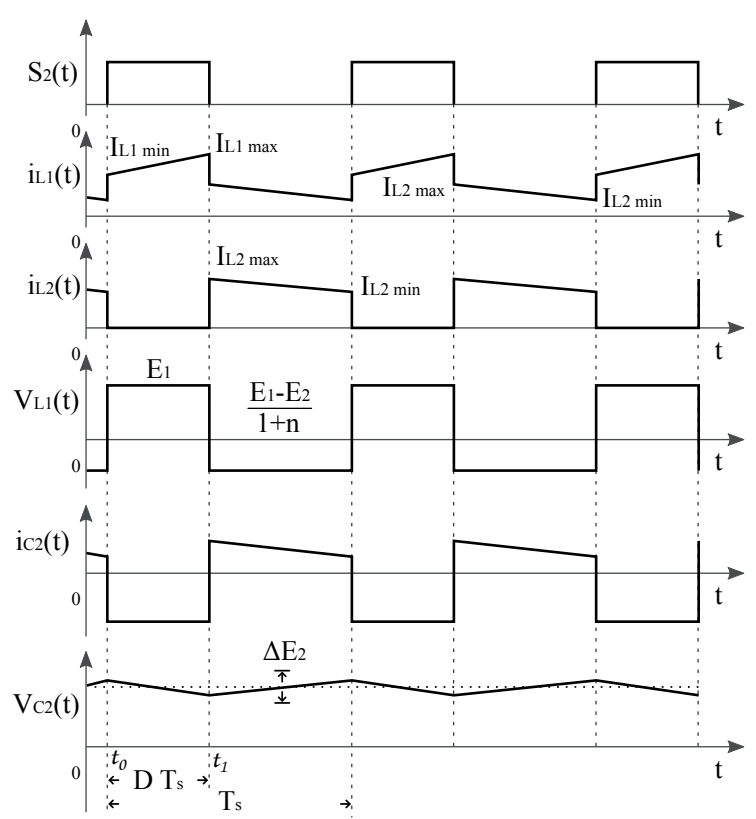

Fig. 4. Idealized waveforms of proposed topology for forward operating mode.

is flowing through the switches $S_{1}, S_{2}$ and inductor $L_{1}$, the current in $L_{2}$ is zero and current $i_{L 1}$ increases linearly. The voltages across the inductors $L_{1}$ and $L_{2}$ are $E_{1}$ and $n \cdot E_{1}$, respectively. The load $R_{2}$ receives energy from the output capacitor $C_{2}$. The equivalent circuit of first stage is illustrated in Figure 3.a.

$2^{\mathrm{o}}$ stage $\left[D T_{S}-T_{S}\right]$ : Starts when switch $S_{2}$ is turned-off and the internal diode of $S_{3}$ is forward biased. The currents $i_{L 1}$ and $i_{L 2}$ decrease linearly. The voltages across $L_{1}$ and $L_{2}$ decrease linearly. The voltages across $L_{1}$ and $L_{2}$ are $\left(E_{1}-E_{2}\right) /(1+n)$ and $\left(E_{1}-E_{2}\right) \cdot n /(1+n)$, respectively. The energy stored in the coupled inductor is transferred to the load $R_{2}$ through $L_{2}$ and internal diode of $S_{3}$. Furthermore, the output current $i_{R 2}$ is equal $i_{L 2}-i_{C 2}$. The equivalent circuit of second stage can be seen in the Figure 3.b.

1) DC Voltage Gain for Forward Mode: The expression for the DC voltage gain for CCM, can be given from the analysis of the average voltage across the inductor winding $L_{1}$.

$$
V_{L 1_{A V G}}=\frac{1}{T_{s}} \cdot\left[\int_{0}^{D T_{s}} E_{1} d t+\int_{D T_{s}}^{T_{s}} \frac{E_{1}-E_{2}}{1+n} d t\right]=0 .
$$

Rearranging (2), the DC voltage gain in forward operating mode for CCM is presented by (3).

$$
G_{\text {forw }}=\frac{E_{2}}{E_{1}}=\frac{1+n \cdot D}{1-D} .
$$

The DC voltage gain of the proposed converter in forward operating mode $\left(G_{\text {forw }}\right)$ is exposed graphically in Figure 5 for different $n$ condition and, compared to the conventional Boost converter, where $G_{\text {Boost }}=1 / 1-D$.

2) Inductor Current Ripple for Forward Mode: The current ripple $\Delta I_{L 1}$ in the inductor $L_{1}$ can be obtained from the first stage, which is important to determine the inductance value of 


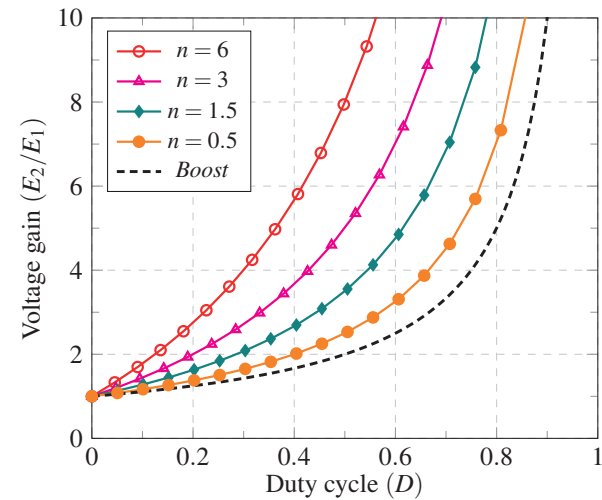

Fig. 5. DC voltage gain in forward operating mode for CCM.

the coupled inductor.

$$
v_{L 1}=L_{1} \cdot \frac{\Delta I_{L 1}}{d t} ; \quad \Delta I_{L 1}=\frac{E_{1} \cdot D}{L_{1} \cdot f_{s}} .
$$

Equation (4) can be used to calculate the inductance value of $L_{1}$ and $L_{2}$, as shown in the following expressions:

$$
L_{1}=\frac{E_{1} \cdot D}{\Delta I_{L 1} \cdot f_{s}} ; \quad L_{2}=L_{1} \cdot n^{2} .
$$

3) Output Capacitor Voltage Ripple: Voltage ripple of the output capacitors $\Delta E_{2}$ against the available charge $\Delta Q$, is expressed as follows:

$$
\Delta E_{2}=\Delta V_{C 2}=\frac{\Delta Q}{C_{2}}=\frac{I_{C 2} \cdot \Delta t}{C_{2}} .
$$

During the first stage, the capacitor current $I_{C 2}$ is equal to the output current $I_{2}$. The interval time is equal to $D \cdot T_{s}$, after replacing that in the (6), the output voltage ripple is given by (7).

$$
\Delta E_{2}=\frac{I_{2} \cdot D}{C_{2} \cdot f_{s}} .
$$

Through expression (7), the capacitance value can then be determined.

4) Components' Stress Calculation for Forward Mode: The RMS value of capacitor current $C_{2}$ can be calculated by (8).

$$
I_{C 2}=\sqrt{\frac{1}{T_{s}} \cdot\left[\int_{0}^{D T_{s}}\left(I_{2}\right)^{2} d t+\int_{D T_{s}}^{T_{s}}\left(\frac{I_{2}}{1-D}-I_{2}\right)^{2} d t\right]} .
$$

Through expression (8), the RMS current in the capacitor $C_{2}$ is calculated by (9).

$$
I_{C 2}=I_{2} \cdot \sqrt{\frac{D}{1-D}}
$$

The average and RMS current values through $L_{1}$ can be expressed by (10).

$$
I_{L 1_{(A V G)}}=I_{1} ; \quad I_{L 1_{(R M S)}}=\frac{I_{2}}{1-D} \cdot \sqrt{(2+n) n \cdot D+1} .
$$

The average and RMS current values through $L_{2}$ can be expressed by (11).

$$
I_{L 2_{(A V G)}}=I_{2} ; \quad I_{L 2_{(R M S)}}=\frac{I_{2}}{\sqrt{1-D}} .
$$

The current stresses of switch $S_{1}$ can be expressed by (12). As the switch is constantly conducting, its drain-source voltage is equal to zero.

$$
I_{S 1_{(A V G)}}=I_{1} ; \quad I_{S 1_{(R M S)}}=\frac{I_{2}}{1-D} \cdot \sqrt{(2+n) \cdot n \cdot D+1} .
$$

The current and voltage stresses on switch $S_{2}$ are give by (13) and (14), respectively.

$$
\begin{gathered}
I_{S 2_{(A V G)}}=I_{1}-I_{2} ; \quad I_{S 2_{(R M S)}}=\frac{I_{1}-I_{2}}{\sqrt{D}} . \\
V_{S 2}=\frac{E_{1} \cdot n+E_{2}}{1+n} .
\end{gathered}
$$

The current and voltage stresses at switch $S_{3}$ are give by (15) and (16).

$$
\begin{gathered}
I_{S 3_{(A V G)}}=I_{2} ; \quad I_{S 3_{(R M S)}}=\frac{I_{2}}{\sqrt{1-D}} . \\
V_{S 3}=E_{1}+E_{2} \cdot n .
\end{gathered}
$$

\section{B. Backward Operating Mode ( $E_{2}$ to $\left.E_{1}\right)$}

In backward operating mode, the proposed topology presents two topological stages for CCM in each switching period $T_{s}$, according to Figure 6 . Following the description of the operating principle and idealized waveforms are presented.

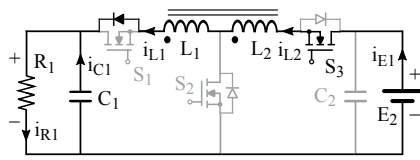

a)

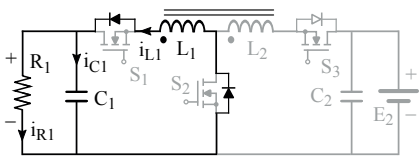

b)
Fig. 6. Topological stages in backward operating mode for CCM: a) First stage, and b) Second stage.

$1^{\mathrm{o}}$ stage $\left[0-D T_{S}\right]$ : In $t=0$, the switch $S_{3}$ is turned on, and the coupled inductor windings store energy. The input current $I_{2}$ is flowing through the internal diode of $S_{1}, S_{3}, L_{2}$, and $L_{1}$. The voltages across $L_{2}$ and $L_{1}$ are equal to $\left(E_{2}-E_{1}\right) \cdot n /(1+n)$ and $\left(E_{2}-E_{1}\right) /(1+n)$, respectively. The load $R_{1}$ and output capacitor $C_{1}$ receive energy from the inductor $L_{1}$ through the internal diode of $S_{1}$. The equivalent circuit of the first stage is illustrated in Figure 6.a.

$2^{\circ}$ stage $\left[D T_{S}-T_{S}\right]$ : This stage starts at instant $t=D \cdot T_{S}$, the switch $S_{3}$ is turned off, and the internal diode of $S_{2}$ is forward biased. The current $i_{L 2}$ is zero, and $i_{L 1}$ decreases linearly. The voltage inductor across $L_{2}$ and $L_{1}$ are equal $n \cdot E_{1}$ and $E_{1}$, respectively. The energy stored in the coupled inductor is transferred to the load $R_{1}$ through inductor $L_{1}$ and internal diode of $S_{1}$ and $S_{2}$. Additionally, the output current is $i_{L 1}-i_{C 1}$ and the input current is equal to zero. The equivalent circuit of the second stage is illustrated in Figure 6.b.

Figure 7 illustrates the main idealized waveforms of proposed topology in backward operating mode. 


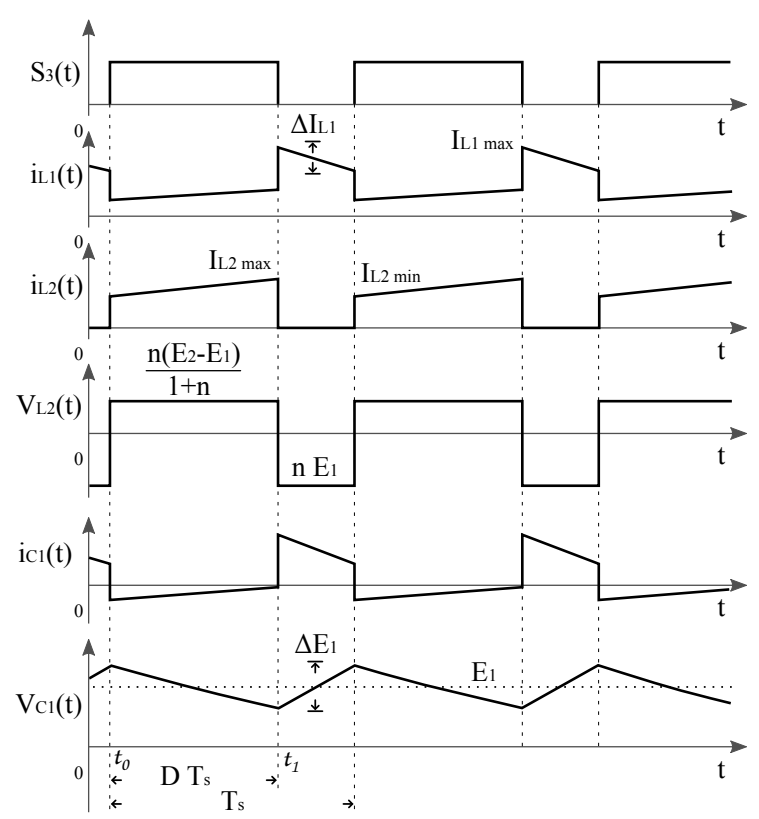

Fig. 7. Idealized waveforms in backward operating mode for CCM.

1) DC Voltage Gain for Backward Mode: Considering the proposed topology is operating in steady state, CCM and backward operating mode, the average voltage across inductor winding $L_{2}$ should be zero for a switching period. Then the DC voltage gain can be given from (17).

$$
V_{L 2_{A V G}}=\frac{1}{T_{s}} \cdot\left[\int_{0}^{D T_{s}} \frac{\left(E_{2}-E_{1}\right) \cdot n}{1+n} d t+\int_{D T_{s}}^{T_{s}}-n \cdot E_{1} d t\right] .
$$

Manipulating the average voltage of the inductor $V_{L 2}=0$, the DC voltage gain in the backward operating mode is calculated by (18).

$$
G_{b a c k}=\frac{E_{1}}{E_{2}}=\frac{D}{(1+n)-n \cdot D} .
$$

The DC voltage gain of the proposed topology in backward operating mode is shown graphically in Figure 8, and compared to the conventional Buck converter.

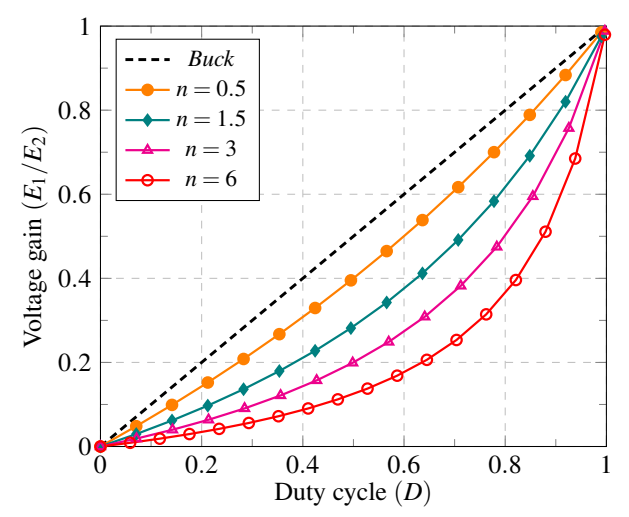

Fig. 8. DC voltage gain in backward operating mode for CCM.

2) Inductor Current Ripple for Backward Mode: The inductor current ripple in CCM can be calculated during the second stage. From Figure 7, the inductor current ripple is obtained, which is given by (19).

$$
v_{L 2}=L_{2} \cdot \frac{\Delta I_{L 2}}{d t} ; \quad \Delta I_{L 2}=\frac{\left(E_{2}-E_{1}\right) \cdot n \cdot D}{(1+n) \cdot L_{2} \cdot f_{s}} .
$$

From (19), the inductance values of $L_{2}$ and $L_{1}$ are calculated by (20).

$$
L_{2}=\frac{\left(E_{2}-E_{1}\right) \cdot n \cdot D}{(1+n) \cdot \Delta I_{L 2} \cdot f_{s}} ; \quad L_{1}=\frac{L_{2}}{n^{2}}
$$

3) Output Capacitor Voltage Ripple: In the previous analysis, the output capacitor is assumed to be very large to keep their voltages constant. In practice, the voltages cannot be kept constant with a finite capacitance value. Thus, there is inevitably a voltage ripple over it. The relationship of the voltage ripple and the capacitance is given by (21).

$$
\Delta V_{C 1}=\Delta E_{1}=\frac{\Delta Q}{C_{1}} .
$$

The output capacitor $C_{1}$ is discharged by the load current $I_{1}$ during the second stage. The total time is equal to $(1-D) \cdot T_{s}$. Therefore, the voltage ripple can be obtained by (22).

$$
\Delta E_{1}=\frac{I_{1} \cdot D-I_{2}}{C_{1} \cdot f_{s}} .
$$

Through expression (22), the capacitance value can then be determined.

4) Components' Stress Calculation for Backward Mode: The mathematical expression that describing the RMS value of capacitor current can be given by:

$$
I_{C 1}=\sqrt{\frac{1}{T_{s}} \cdot\left[\int_{0}^{D T_{s}}\left(I_{1}-\frac{I_{2}}{D}\right)^{2} d t+\int_{D T_{s}}^{T_{s}}\left(\frac{I_{1}-I_{2}}{1-D}-I_{2}\right)^{2} d t\right]} .
$$

Through expression (23), the RMS current is calculated by (24).

$$
I_{C 1}=\left(I_{1} \cdot D-I_{2}\right) \cdot \sqrt{\frac{1}{(1-D) \cdot D}} .
$$

The average and RMS values of the current through $L_{2}$ can be expressed by (25).

$$
I_{L 2_{(A V G)}}=I_{2} ; \quad I_{L 2_{(R M S)}}=\frac{I_{2}}{\sqrt{D}} .
$$

The average and RMS values of the current through $L_{1}$ can be expressed by (26).

$$
I_{L 1_{(A V G)}}=I_{1} ; \quad I_{L 1_{(R M S)}}=\sqrt{\frac{I_{2}^{2}}{D}+\frac{\left(I_{1}-I_{2}\right)^{2}}{1-D}} .
$$

The average and RMS values of the current through switch $S_{1}$ are defined by (27). During this operation mode, the switch will remain permanently "ON", so the drain-source voltage is 
TABLE I

Comparison with Simulated and Calculated Values

\begin{tabular}{|c|c|c|c|c|c|c|c|c|c|c|c|c|c|c|c|c|}
\hline & Parameter & $\Delta I_{L}$ & $\Delta V_{C}$ & $I_{C_{(R M S)}}$ & $I_{L 1_{(A V G)}}$ & $I_{L 1_{(R M S)}}$ & $I_{L 2_{(A V G)}}$ & $I_{L 2_{(R M S)}}$ & $I_{S 1_{(A V G)}}$ & $I_{S 1_{(R M S)}}$ & $I_{S 2_{(A V G)}}$ & $I_{S 2_{(R M S)}}$ & $V_{S 2}$ & $I_{S 3_{(A V G)}}$ & $I_{S 3_{(R M S)}}$ & $V_{S 3}$ \\
\hline \multirow{2}{*}{$\begin{array}{l}\text { forward } \\
\text { mode }\end{array}$} & calculated & $7.6 A$ & $2.8 \mathrm{~V}$ & $1.8 \mathrm{~A}$ & $6 A$ & $6.6 A$ & $2 A$ & $2.7 \mathrm{~A}$ & $6 A$ & $6.6 A$ & $4 A$ & $6 A$ & $178.5 \mathrm{~V}$ & $2 A$ & $2.7 A$ & $565 \mathrm{~V}$ \\
\hline & simulated & $7.5 A$ & $2.63 \mathrm{~V}$ & $1.75 A$ & $6 A$ & $6.48 A$ & $2 A$ & $2.64 A$ & $6 A$ & $6.52 A$ & $4 A$ & $5.96 A$ & $172 \mathrm{~V}$ & $2 A$ & $2.63 A$ & $558 \mathrm{~V}$ \\
\hline \multirow{2}{*}{$\begin{array}{l}\text { backward } \\
\text { mode }\end{array}$} & calculated & $5 A$ & $0.6 \mathrm{~V}$ & $2.7 A$ & $6 A$ & $6.6 A$ & $2 A$ & $2.7 A$ & $6 A$ & $6.6 A$ & $4 A$ & $5.3 A$ & $178.5 \mathrm{~V}$ & $2 A$ & $2.7 A$ & $455 \mathrm{~V}$ \\
\hline & simulated & $4.8 A$ & $0.52 \mathrm{~V}$ & $2.4 A$ & $6 A$ & $6.53 A$ & $2 A$ & $2.64 A$ & $6 A$ & $6.46 A$ & $4 A$ & $5.2 A$ & $175 \mathrm{~V}$ & $2 A$ & $2.58 A$ & $448 \mathrm{~V}$ \\
\hline
\end{tabular}

zero.

$$
I_{S 1_{(A V G)}}=I_{1} ; \quad I_{S 1_{(R M S)}}=\sqrt{\frac{I_{2}^{2}}{D}+\frac{\left(I_{1}-I_{2}\right)^{2}}{1-D}} .
$$

The current and voltage stresses of switch $S_{2}$ are give by (28) and (29), respectively.

$$
\begin{gathered}
I_{S 2_{(A V G)}}=I_{1}-I_{2} ; \quad I_{S 2_{(R M S)}}=\frac{I_{1}-I_{2}}{\sqrt{D}} . \\
V_{S 2}=E_{2}+\frac{\left(E_{1}-E_{2}\right) \cdot n}{1+n} .
\end{gathered}
$$

Based on the aforementioned operation analyses, the current and voltage stress of switches $S_{3}$ can be obtained directly as follows:

$$
\begin{gathered}
I_{S 3_{(A V G)}}=I_{2} ; \quad I_{S 3_{(R M S)}}=\frac{I_{2}}{\sqrt{D}} . \\
V_{S 3}=E_{2}+E_{1} \cdot n .
\end{gathered}
$$

Table I shows the comparison between the calculated values with the numerical simulation of the circuit for evaluating all the mathematical expressions. By wich, it is verified that the presented equations are able to correctly represent de operation of the converter.

In Table II the proposed converter is compared with similar topologies that have a single coupled inductor and bidirectional power flow, presented in [18]-[26]. The comparison is made in terms of voltage gain, number of components, voltage stress and soft switching performance. It should be noted that the voltage is compared for same $E_{1}$ and $E_{2}$ and the leakage inductance of coupled-inductors based converters is ignored. The proposed converter offers the following improvement over those reported; low device count, good voltage gain ratio, less device voltage stress and substantial increase in utility rate of magnetic core.

\section{EXPERIMENTAL RESULTS}

Initial investigation of the steady-state operation analysis is provided, in order to verify the operation and adequately evaluate the performance of the proposed converter, a $600 \mathrm{~W}$ prototype was designed and verified experimentally. The converter specifications are exposed in Table III. A photograph of the implemented prototype is exhibited in Figure 9. The PWM modulation was generated on LAUNCHXL-F28377S C2000 LaunchPad.

The experimental waveforms are obtained from the prototype operating in both modes of operation. For the suppression and damping of voltage spikes produced by the leakage inductance of the coupled inductor, a RCD-type circuit (snubber) was connected in parallel to switch $S_{2}$ and another RC series circuit was connected in parallel with $S_{3}$ [27].

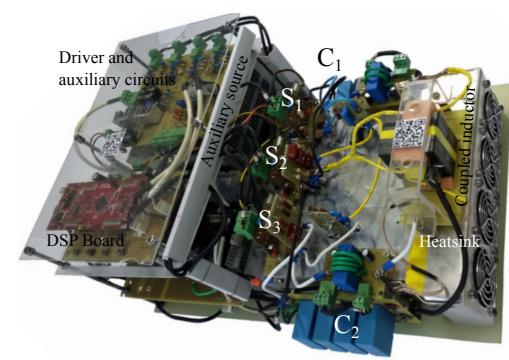

Fig. 9. Experimental prototype of proposed converter.

Figure 10 shows the experimental results when the converter operates in forward mode.

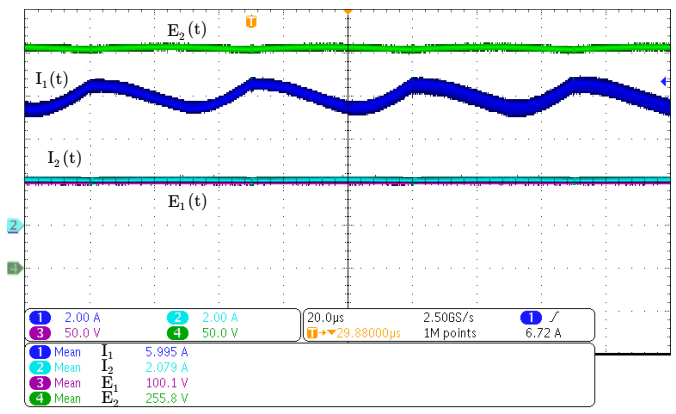

Fig. 10. Currents and voltages in the load and power supply for forward operation $\left(E_{1}=100 \mathrm{~V}, E_{2}=256 \mathrm{~V}\right)$.

Figure 11 shows the waveforms in the coupled inductor for forward operating mode. It is confirmed that converter presents two operating stages in CCM. Moreover, there is a great similarity between experimental and theoretical waveforms. The waveforms were obtained for a duty cycle of $D=0.45$. In this case, the converter is operating in the step-up voltage mode.

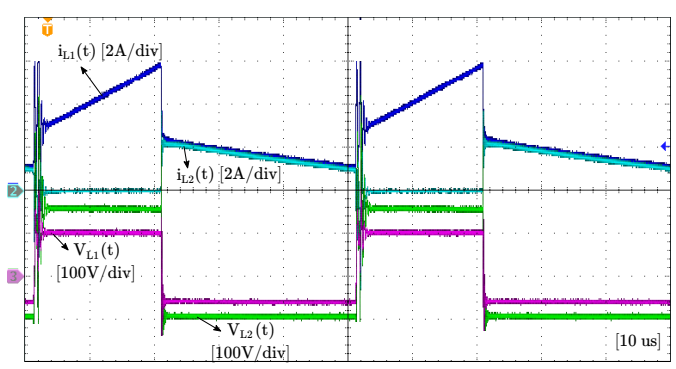

Fig. 11. Voltage and current waveforms in the coupled inductor for forward operation; $C h 1$ - current $i_{L 1}(t), C h 2$ - current $i_{L 2}(t), C h 3$ voltage $V_{L 1}(t)$ and, $C h 4$ - voltage $V_{L 2}(t)$.

The voltage and current of switch $S_{2}$ and diode $D_{3}$ are shown in Figures 12 and 13, respectively. 
TABLE II

Comparison of the Proposed Topology with the Existing Coupled Inductor Converters

\begin{tabular}{|c|c|c|c|c|c|c|c|c|c|c|}
\hline Topology & {$[18]$} & [19] & [20] & [21] & {$[22]$} & [23] & [24] & [25] & [26] & proposed \\
\hline $\begin{array}{r}\mathrm{no} \text { of components } \\
\text { Switch / Diode / } \\
\text { Capacitor }\end{array}$ & $3 / 3 / 3$ & $4 / 4 / 4$ & $3 / 4 / 3$ & $4 / 4 / 4$ & $4 / 4 / 4$ & $4 / 4 / 5$ & $4 / 4 / 4$ & $4 / 4 / 4$ & $3 / 3 / 2$ & $3 / 3 / 2$ \\
\hline $\begin{array}{r}\text { Step-up } \\
\text { voltage gain }\end{array}$ & $\frac{2+n-D}{1-D}$ & $\frac{n k+2}{1-D}$ & $\frac{n}{1-D}$ & $\frac{2 n-1}{(n-1)(1-D)}$ & $\frac{n+1}{1-D}$ & $\frac{1+n}{1-D}$ & $\frac{2+n}{1-D}$ & $\frac{1+n}{1-D}$ & $\frac{1+D}{1-D}$ & $\frac{1+n D}{1-D}$ \\
\hline $\begin{array}{r}\text { Step-down } \\
\text { voltage gain }\end{array}$ & $\frac{1-D}{2+n-D}$ & $\frac{D}{n k+2}$ & $\frac{2 D(1+n)-1}{n^{2}(1-D)+3 n}$ & $\frac{(n-1) D}{2 n-1}$ & $\frac{D}{1+n}$ & No presented & $\frac{1-D}{n+2}$ & $n D$ & $\frac{D}{2-D}$ & $\frac{D}{(1+n)-n D}$ \\
\hline $\begin{array}{r}\text { Voltage stress } \\
\text { on switches }\end{array}$ & $\begin{array}{c}V_{S 1}=\frac{E_{1}}{1-D} \\
V_{S 2}=\frac{(1+n) E_{1}}{1-D} \\
V_{S 3}\end{array}$ & $\begin{array}{c}V_{S 1}=\frac{E_{1}}{1-D} \\
V_{S 2} \\
V_{S 3}=\frac{(1+n) E_{1}}{1-D} \\
V_{S 4}\end{array}$ & $\begin{array}{c}V_{S 1}=n E_{1} \\
V_{S 2} D E_{1} \\
V_{S 3}=\frac{n D E_{1}}{1-D}+n E_{1}\end{array}$ & $\begin{array}{c}V_{S 1}=\frac{(n-1) E_{2}}{2 n-1} \\
V_{S 2} \\
V_{S 3}=E_{2}-\frac{(n-1) E_{2}}{2 n-1}\end{array}$ & $\begin{array}{l}V_{S 1}=\frac{E_{1}}{1-D} \\
V_{S 2} \\
V_{S 3}=2 n E_{1} \\
V_{S 4}=n V_{S 1}\end{array}$ & $\begin{array}{c}V_{S 1}=\frac{E_{1}}{1-D} \\
V_{S 2}=E_{1} \\
V_{S 3}=E_{2}-\frac{E_{1}}{1-D}\end{array}$ & $\begin{array}{c}V_{S 1}=\frac{E_{1}}{1-D} \\
V_{S 2}=E_{1} \\
V_{S 3}=E_{2}-\frac{E_{1}}{1-D}\end{array}$ & $\begin{array}{c}V_{S 1}=E_{2} \\
V_{S 2}=E_{1} \\
V_{S 4}=\frac{E_{1}}{1-D}\end{array}$ & $\begin{array}{l}V_{S 1}=\frac{E_{1}+E_{2}}{2} \\
V_{S 2} \\
V_{S 3}=E_{1}+E_{2}\end{array}$ & $\begin{aligned} V_{S 1} & =E_{2}-E_{1} \\
V_{S 2} & =\frac{n E_{1}+E_{2}}{1+n} \\
V_{S 3} & =E_{1}+n E_{2}\end{aligned}$ \\
\hline
\end{tabular}

TABLE III

Main Prototype Specifications and Parameters

\begin{tabular}{rc}
\hline \multicolumn{1}{c}{ Parameters } & Value \\
\hline Rated power $(P):$ & $600 \mathrm{~W}$ \\
\hline Low voltage $\left(E_{1}\right):$ & $100 \mathrm{~V}$ \\
\hline High voltage $\left(E_{2}\right):$ & $300 \mathrm{~V}$ \\
\hline Current ripple $\left(\Delta I_{L 1}\right):$ & $7 \mathrm{~A}$ \\
\hline Switching frequency $\left(f_{S}\right):$ & $20 \mathrm{kHz}$ \\
\hline Turns ratio $\left(n, n_{2} / n_{1}\right):$ & $1.55,17$ turns $/ 11$ turns $-38 \mathrm{AWG}$ Litz wire \\
\hline Duty cycle $(D):$ & forward mode $(0.45) /$ backward mode $(0.58)$ \\
\hline Inductance $\left(L_{1} / L_{2}\right):$ & $288 \mu \mathrm{H} / 691 \mu \mathrm{H}$ \\
\hline Magnetic Core $:$ & $2 \times \mathrm{NEE}-55$ ferrite by Thornton \\
\hline Capacitance $\left(C_{1} / C_{2}\right):$ & $120 \mu \mathrm{F}-450 \mathrm{~V} / 15.6 \mu \mathrm{F}-630 \mathrm{~V}$ by KEMET \\
\hline Switches $\left(S_{1}, S_{2}, S_{3}\right):$ & $\mathrm{SCH} 2080 \mathrm{KE}$ by ROHM \\
\hline Snubber $(R C D+R C):$ & $68 k \Omega, 220 n \mathrm{~F}, \mathrm{FR} 207+120 \Omega, 0.56 n \mathrm{~F}$ \\
\hline
\end{tabular}

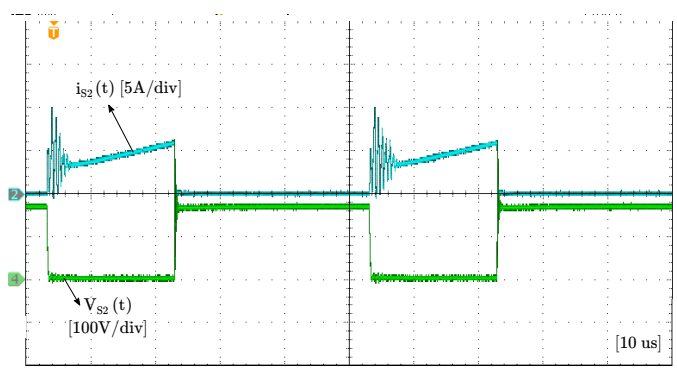

Fig. 12. Voltage and current waveforms in the switch $S_{2}$ for forward operation: $C h 2$ - current $i_{S 2}(t)$ and, $C h 4$ - voltage $V_{S 2}(t)$.

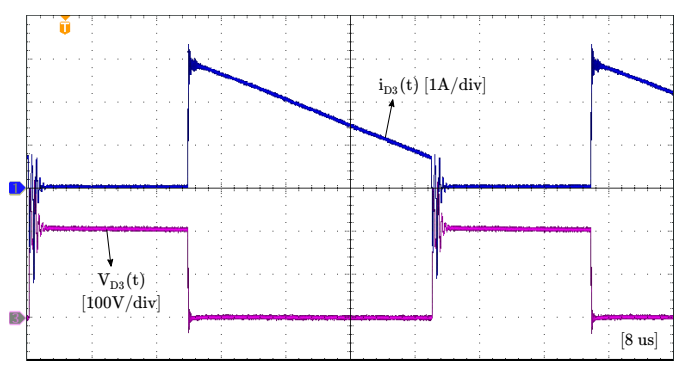

Fig. 13. Voltage and current waveforms in the diode $D_{3}$ for forward operation: $C h 1$ - current $i_{D 3}(t)$ and, $C h 3$ - voltage $V_{D 3}(t)$.

In Figure 14 is presented an experimental result that shows in detail the voltage and the current in the capacitor $C_{2}$. In this result, it is verified that the voltage applied to the load is stabilized and with low ripple.

Figures 15-18 show the experimental results that correspond to the operation in the backward mode.

In Figure 15, the voltages and the windings currents of the coupled inductor are shown for backward operating mode $\left(E_{2}=300 \mathrm{~V}, E_{1}=100 \mathrm{~V}\right)$. It is observed that the converter also

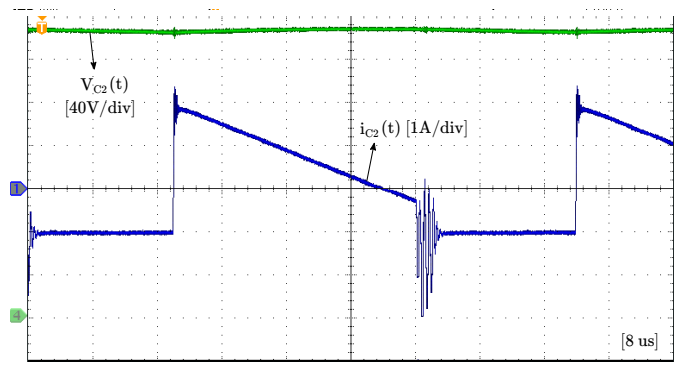

Fig. 14. Voltage and current waveforms in the capacitor $C_{2}$ for forward operation: $C h 1$ - current $i_{C 2}(t)$ and, $C h 4$ - voltage $V_{C 2}(t)$.

operates in CCM. In this case, it is operating in the step-down voltage mode with a duty cycle of $D=0.58$.

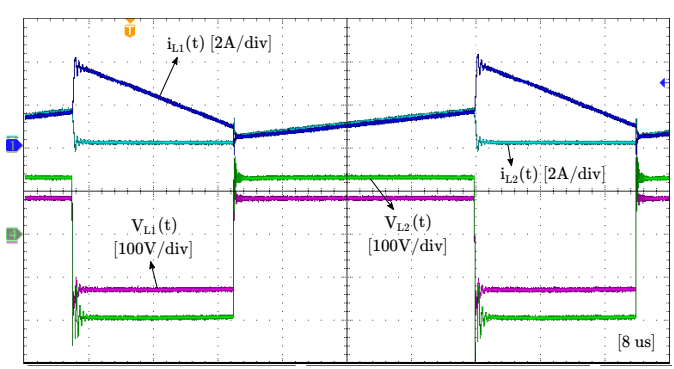

Fig. 15. Voltage and current waveforms in the coupled inductor for backward operation; $C h 1$ - current $i_{L 1}(t), C h 2$ - current $i_{L 2}(t), C h 3$ voltage $V_{L 1}(t)$ and, $C h 4$ - voltage $V_{L 2}(t)$.

Figure 16 shows the blocking voltage on diode $D_{2}$ and its current $i_{D 2}(t)$ for backward operation. Figure 17 shows the blocking voltage on switch $S_{3}$ and its current $i_{S 3}(t)$.

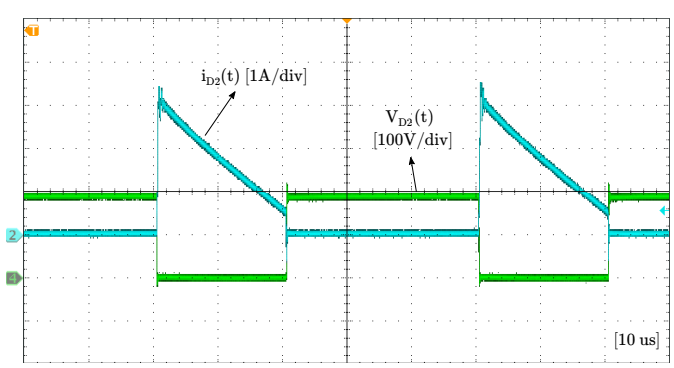

Fig. 16. Voltage and current waveforms in the diode $D_{2}$ for backward operation: $C h 2$ - current $i_{D 2}(t)$ and, $C h 4$ - voltage $V_{D 2}(t)$.

Figure 18 shows the capacitor voltage $V_{C 1}(t)$ and its current $i_{C 1}(t)$. The capacitor voltage is same as $E_{1}$ and is continuous with low ripple.

The results confirmed that the proposed dc-dc converter can be used as a step-up and step-down converter. In addition, it 


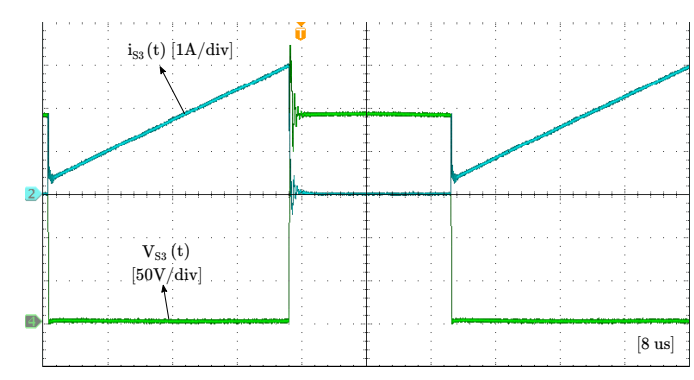

Fig. 17. Voltage and current waveforms in the switch $S_{3}$ for backward operation: $C h 2$ - current $i_{S 3}(t)$ and, $C h 4$ - voltage $V_{S 3}(t)$.

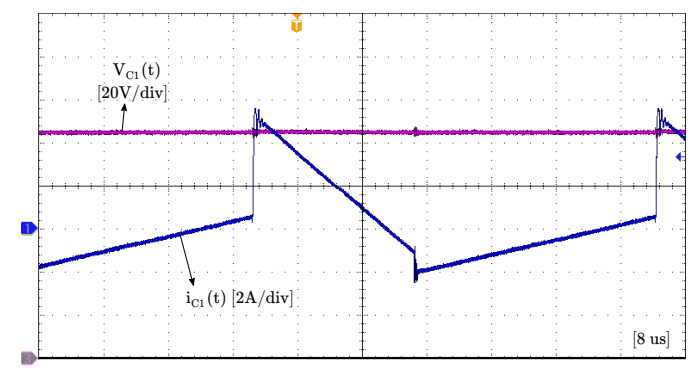

Fig. 18. Waveforms in the capacitor $C_{1}$ for backward operation: $C h 1$ current $i_{C 1}(t)$ and, $C h 3$ - voltage $V_{C 1}(t)$.

allows a wide range of applications that require bidirectional power flow and a wide range of regulation of the dc-bus.

\section{CONCLUSIONS}

This paper presented a dc-dc bidirectional converter with coupled inductor for dc-microgrid applications where dc voltage of source varies in a wide range. The paper discussed operating principle, equivalent circuits, theoretical waveforms and mathematical analysis of the proposed converter. From the experiment result, it was verified that the proposed dc-dc converter is bidirectional, it allows a wide output voltage range and greater dc voltage gain is compared with the traditionals Buck and Boost converters.

The topology merges the main characteristics of Boost and Buck dc-dc converters, resulting in a converter with small volume, low weight and reduced number of components. It has advantages in terms of dc voltage gain without any isolation and can better handle the dc bus voltage regulation. Moreover, the converter is competitive and qualified for energy storage elements, such as batteries, and ultracapacitors with the high voltage dc bus in electric vehicles. The experimental results with resistive loads, in forward and backward modes, verified the operating of the proposed converter, when bidirectional power flow is required and a good voltage regulation of the dc bus is essential.

\section{ACKNOWLEDGEMENTS}

The authors thank to Universidade do Estado de Santa Catarina - UDESC, the Coordenação de Aperfeiçoamento de Pessoal de Nível Superior - Brasil (CAPES), the MCTIC and CTI Renato Archer for providing institutional resources to this research and technical support. This research registered a patent number BR 102018 010019-0 of intellectual property under the domain of the Fundação Universidade do Estado de Santa Catarina - UDESC.

\section{REFERENCES}

[1] F. Nejabatkhah, Y.-W. Li, "Overview of power management strategies of hybrid AC/DC microgrid", IEEE Transactions on Power Electronics, vol. 30, no. 12, pp. 7072-7089, Dec. 2015.

[2] A. Francés, R. Asensi, Ó. García, R. Prieto, J. Uceda, "Modeling electronic power converters in smart DC microgrids-An overview", IEEE Transactions on Smart Grid, vol. 9, no. 6, pp. 6274-6287, Nov. 2018.

[3] T. Shah, Z. A. Ansari, "An Overview of Intelligent Energy Management System for DC Microgrid: System and Communication Architecture and Application in Power Distribution System", in 2018 IEEE 13th International Conference on Industrial and Information Systems (ICIIS), pp. 1-4, IEEE, 2018.

[4] D. Bourner, "Bidirectional DC-DC converter systems: sustaining power component design methodology to achieve critical power conditioning", IEEE Power Electronics Magazine, vol. 5, no. 2, pp. 66-71, June 2018.

[5] Y. Han, X. Xie, H. Deng, W. Ma, "Central energy management method for photovoltaic DC microgrid system based on power tracking control", IET Renewable Power Generation, vol. 11, no. 8, pp. 11381147, 2862017.

[6] S. Dahale, A. Das, N. M. Pindoriya, S. Rajendran, "An overview of DC-DC converter topologies and controls in DC microgrid", in 2017 7th International Conference on Power Systems (ICPS), pp. 410-415, IEEE, 2017.

[7] N. Elsayad, H. Moradisizkoohi, O. A. Mohammed, "Design and implementation of a new transformerless bidirectional DC-DC converter with wide conversion ratios", IEEE Transactions on Industrial Electronics, vol. 66, no. 9, pp. 7067-7077, Sept. 2019.

[8] X. Shen, D. Tan, Z. Shuai, A. Luo, "Control Techniques for Bidirectional Interlinking Converters in Hybrid Microgrids: Leveraging the advantages of both ac and dc", IEEE Power Electronics Magazine, vol. 6, no. 3, pp. 39-47, Sept. 2019.

[9] H. Chen, H. Kim, R. Erickson, D. Maksimović, "Electrified automotive powertrain architecture using composite dc-dc converters", IEEE Transactions on Power Electronics, vol. 32, no. 1, pp. 98-116, Jan. 2017.

[10] J. Cao, A. Emadi, "A new battery/ultracapacitor hybrid energy storage system for electric, hybrid, and plug-in hybrid electric vehicles", IEEE Transactions on power electronics, vol. 27, no. 1, pp. 122-132, Jan. 2012.

[11] H. Plesko, J. Biela, J. Luomi, J. W. Kolar, "Novel concepts for integrating the electric drive and auxiliary DC-DC converter for hybrid vehicles", IEEE Transactions on power electronics, vol. 23, no. 6, pp. 3025-3034, Nov. 2008.

[12] M. B. El Kattel, R. Mayer, S. V. G. Oliveira, "Isolated step-up/step-down three-phase dc-dc converter with high frequency", Eletrônica de Potência - SOBRAEP, vol. 23, no. 4, pp. 454-465, out./dez. 2018. 
[13] M. B. da Rosa, M. B. El Kattel, R. Mayer, M. D. Possamai, S. V. G. Oliveira, "Analysis and simulation of a novel coupled inductor bidirectional dc-dc converter", in 2017 Brazilian Power Electronics Conference (COBEP), pp. 1-6, IEEE, 2017.

[14] Y. Du, X. Zhou, S. Bai, S. Lukic, A. Huang, "Review of non-isolated bi-directional DC-DC converters for plugin hybrid electric vehicle charge station application at municipal parking decks", in 2010 Twenty-Fifth Annual IEEE Applied Power Electronics Conference and Exposition (APEC), pp. 1145-1151, IEEE, 2010.

[15] O. C. Onar, J. Kobayashi, A. Khaligh, "A fully directional universal power electronic interface for $\mathrm{EV}$, HEV, and PHEV applications", IEEE Transactions on Power Electronics, vol. 28, no. 12, pp. 5489-5498, Dec. 2013.

[16] C.-C. Lin, L.-S. Yang, G. Wu, "Study of a nonisolated bidirectional DC-DC converter", IET Power Electronics, vol. 6, no. 1, pp. 30-37, Jan. 2013.

[17] R. Mayer, M. B. El Kattel, M. D. Possamai, C. Bruning, S. V. G. Oliveira, "Analysis of a multi-phase interleaved bidirectional DC/DC power converter with coupled inductor", in 2017 Brazilian Power Electronics Conference (COBEP), pp. 1-6, IEEE, 2017.

[18] A. Ayachit, S. U. Hasan, Y. P. Siwakoti, M. Abdul-Hak, M. K. Kazimierczuk, F. Blaabjerg, "Coupled-Inductor Bidirectional DC-DC Converter for EV Charging Applications with Wide Voltage Conversion Ratio and Low Parts Count", in 2019 IEEE Energy Conversion Congress and Exposition (ECCE), pp. 1174-1179, IEEE, 2019.

[19] Z. Hosseinzadeh, N. Molavi, H. Farzanehfard, "SoftSwitching High Step-Up/Down Bidirectional DCDC Converter", IEEE Transactions on Industrial Electronics, vol. 66, no. 6, pp. 4379-4386, June 2019.

[20] C.-M. Hong, L.-S. Yang, T.-J. Liang, J.-F. Chen, "Novel bidirectional DC-DC converter with high step-up/down voltage gain", in 2009 IEEE Energy Conversion Congress and Exposition, pp. 60-66, IEEE, 2009.

[21] H. Liu, L. Wang, Y. Ji, F. Li, "A novel reversal coupled inductor high-conversion-ratio bidirectional DC-DC converter", IEEE Transactions on Power Electronics, vol. 33, no. 6, pp. 4968-4979, June 2018.

[22] S. M. P., M. Das, V. Agarwal, "Design and Development of a Novel High Voltage Gain, HighEfficiency Bidirectional DC-DC Converter for Storage Interface", IEEE Transactions on Industrial Electronics, vol. 66, no. 6, pp. 4490-4501, June 2019.

[23] H. Wu, K. Sun, L. Chen, L. Zhu, Y. Xing, "High StepUp/Step-Down Soft-Switching Bidirectional DCâDC Converter With Coupled-Inductor and Voltage Matching Control for Energy Storage Systems", IEEE Transactions on Industrial Electronics, vol. 63, no. 5, pp. 2892-2903, May 2016.

[24] R.-Y. Duan, J.-D. Lee, "High-efficiency bidirectional DC-DC converter with coupled inductor", IET Power Electronics, vol. 5, no. 1, pp. 115-123, January 2012.
[25] Y. T. Yau, W. Z. Jiang, K. I. Hwu, "Bidirectional operation of high step-down converter", IEEE Transactions on Power Electronics, vol. 30, no. 12, pp. 6829-6844, Dec. 2015.

[26] L. Yang, T. Liang, "Analysis and implementation of a novel bidirectional DC-DC converter", IEEE Transactions on Industrial Electronics, vol. 59, no. 1, pp. 422-434, Jan. 2012.

[27] T. Lagap, E. Dimopoulos, S. Munk-Nielsen, "An RCDD snubber for a bidirectional flyback converter", in 2015 17th European Conference on Power Electronics and Applications (EPE'15 ECCE-Europe), Geneva, pp. 1-10, IEEE, 2015.

\section{BIOGRAPHIES}

Robson Mayer, was born in Saudades, Santa Catarina, Brazil, in 1985. He received the B.S. in electrical engineering from Católica of Santa Catarina (UNERJ), Jaraguá do Sul in 2010, M.Sc degrees in electrical engineering from the Universidade Regional de Blumenau (FURB) in 2014 and Ph.D. degrees in Electrical Engineering from the Santa Catarina State University (UDESC), Joinville, Brazil, in 2019.

He is currently a researcher at the Núcleo de Processamento de Energia Elétrica (nPEE), UDESC, Joinville and at the Center for Information Technology Renato Archer, Campinas, São Paulo, Brazil. His main research interests are power electronics, dc-dc converters, inverters, PFC converters, rectifiers, high power battery chargers and photovoltaic systems. Dr. Mayer is a member of the following society: SOBRAEP.

Menaouar Berrehil El Kattel, Electrotechnical Engineer from Djillali University of Sidi Bel Abbes Liabes, Algeria (2003), and Master in Electrical Engineering from Blumenau Regional University - FURB (2013) and Ph.D. degrees in Electrical Engineering from the Santa Catarina State University - UDESC, Joinville, Brazil (2018).

His topics of interest are three-phase DC-DC converters, soft switching, power electronics applications in electric vehicles and photovoltaic systems. He is a member of the SOBRAEP.

Sérgio Vidal Garcia Oliveira, was born in Lages, SC, Brasil, in 1974. He received the B.S. in electrical engineering from Universidade Regional de Blumenau (FURB) in 1999 and M.Sc. and Dr. degrees in electrical engineering from the Universidade Federal de Santa Catarina (UFSC), Florianópolis, Brasil, in 2001 and 2006, respectively.

$\mathrm{He}$ is a Researcher on power electronics in both, at Universidade Regional de Blumenau (FURB) since 2004 and, at Universidade do Estado de Santa Catarina (UDESC) since 2012. His research interests are: integrated motor drives, solid-state transformers, distributed generation systems, FEM applied in the design of power electronics magnetic devices, cybersecurity on power electronics and electric traction systems. Dr. Oliveira is an IEEE senior member, also is member of: SOBRAEP - Brazilian Power Electronics Society; SBA - Brazilian Automatic Society; IES - Industrial Electronics Society; PELS - Power Electronics Society, and IAS - Industry Applications Society. 